\title{
Metabolic Models of Ruminant Metabolism: Recent Improvements and Current Status ${ }^{1}$
}

\author{
M. D. Hanigan, ${ }^{* 2}$ H. G. Bateman, $\dagger^{3}$ J. G. Fadel, $\neq$ and J. P. McNamara§ \\ *Virginia Polytechnic Institute and State University, Blacksburg 24061 \\ †Department of Dairy Science, Louisiana State University AgCenter, Baton Rouge 70803 \\ ‡Department of Animal Science, University of California, Davis 95616 \\ $\S$ Department of Animal Science, Washington State University, Pullman 99164
}

\begin{abstract}
The NC-1009 regional research project has two broad goals of quantifying the properties of feeds and the metabolic interactions among nutrients that influence nutrient availability for milk production and that alter synthesis of milk, and using those quantitative relationships to challenge and refine computer-based nutrition systems for dairy cattle. The objective of this paper was to review progress in modeling. Significant progress has been made in model refinements over the past $10 \mathrm{yr}$ as exemplified by the most recent NRC model (2001) and work on the Molly model of Baldwin and colleagues (1987). These models have different objectives but share many properties. The level of aggregation of the NRC model (2001) does not allow detailed analyses of specific metabolic reactions that affect nutritional efficiency. The Baldwin model is aggregated at the pathway level and is therefore amenable to assessment with a broad range of biological measurements. Recent improvements to that model include the addition of an ingredient based input scheme, use of in situ data to set ruminal protein degradation rates, and refinement of the representation of mammary cell numbers and activity. Although the Baldwin model appears to be appropriate structurally, several parameters are known to be inadequate. Predictions of ruminal N metabolism and totaltract starch digestions have similar accuracy as the NRC model. However, the NRC more accurately predicts total-tract fiber digestion and both models significantly overpredict total-tract lipid digestion. These errors contribute to overpredictions of weight retention when simulating full lactations with the Baldwin model and may result in performance prediction errors with the NRC model. Limitations remain in the descriptions of metabolism and metabolic regulation of the splanch-
\end{abstract}

\footnotetext{
Received September 26, 2005.

Accepted December 16, 2005.

${ }^{1}$ Presented at the ADSA/ASAS/CSAS Joint Annual Meeting, Cincinnati, OH, July 2005.

${ }^{2}$ Corresponding author: MHanigan@vt.edu

${ }^{3}$ Current address: Akey, Inc., PO Box 5002, Lewisburg, OH 45338.
}

nic, viscera, adipose tissue, body muscle, and mammary tissue. Integration of genetic control mechanisms can expand these efforts to assist genetic selection as well as feeding management decisions.

Key words: model, metabolism, ruminant, dairy cow

\section{INTRODUCTION}

There are approximately 9 million dairy cows in the United States at present (USDA-NASS, 2005), which would be expected to consume in excess of 150,000 metric tons of feed DM per day at an approximate daily cost of $\$ 20$ million. To maximize productivity of these animals, nutrients provided must meet or exceed nutritional requirements. However, feeding nutrients in excess of needs can be detrimental to the environment. Thus, an accurate assessment of both animal requirements and dietary nutrient supply is economically and environmentally important.

A significant proportion of dairy research activity over the past $100 \mathrm{yr}$ has been devoted to assessing nutritive values of feedstuffs and nutritional requirements of dairy cattle in various physiological states. Knowledge gained from these efforts is periodically used to update nutrient supply and requirement prediction equations (NRC, 1978, 1985, 1989, 2001). The NRC system is widely used by dairy nutritionists in the United States, and thus, the knowledge resident in the system influences a significant proportion of dairy cows in the United States. It seems likely that this model will serve as the framework for field use for the near future, and thus, model developmental efforts should ultimately feed into that system until an alternative system is demonstrated to be superior.

The goals of the NC-1009 regional research project are to quantify the properties of feeds and the metabolic interactions among nutrients that influence nutrient availability for milk production and that alter synthesis of milk, and to use those quantitative relationships to challenge and refine computer-based nutrition systems for dairy cattle. The work of the project is broadly geared toward providing information that can be used 
for further development of current requirement systems. This review will focus primarily on summarizing the modeling efforts of individuals involved with the project with reference to other work as needed. Such a narrow focus should not be construed as an indication that work by other scientists is irrelevant to furthering model development; quite the contrary is true. However, due to space limitations and the focus of the symposium, we have chosen to follow the more restrictive path.

Current energy systems, such as NRC (2001), are generally based on the system of Atwater and Bryant (1900). R. L. Baldwin, formerly a member of NC-1009, has summarized historical developments and shortcomings of that system in his book (Baldwin, 1995). These include: 1) poor estimates of basal metabolic requirements, and 2) digestible nutrients from forages do not support the same level of productivity as an equal amount of digestible nutrients from concentrates. Estimates of basal energy expenditures have been greatly improved by statistical derivation of the pertinent parameters. The nonadditivity of forage and concentrate energy has been partially addressed by use of an adjustment factor that scales with dietary energy density. However, such an approach does not totally accommodate the variation that exists among products of digestion with respect to efficiency of conversion to protein, fat, and lactose. Such efficiencies of conversion can vary significantly (Baldwin, 1968). Thus, although prediction errors have likely declined as successive NRC models have been released, there is probably a plateau that cannot be breached with the current approach given such variation in conversion efficiencies.

Improvements in the NRC model have generally been deployed as correction factors applied to existing base equations. That is, the base form of the equations has not changed dramatically over time. These factors have normally been derived within the system by fitting to large input:output data sets collected at the animal level. Because these factors are derived from animal level data, a large amount of data collected at lower levels of function are not utilized in the effort. For example, considerable ruminal metabolism measurements and arteriovenous difference work has been conducted over the past $30 \mathrm{yr}$ and used to better define tissue responses to varying nutrient supply. Yet this data cannot be used directly for parameter estimation efforts within the current NRC scheme, and a mass of new information will be generated from genomic and proteomic efforts in the coming years.

To make use of knowledge of lower level function, one must have models that represent function at the given level of interest. To address such a need, it is tempting to construct a model at the animal level and add extreme detail of lower level function so that the model can be used for all needed predictions. However, such models become so complex that it is difficult or impossible to assess model validity and identify areas where knowledge is lacking or model representation and parameterization are inadequate. A full, detailed model of particle physics is not needed to describe with acceptable accuracy the conversion of dietary energy to milk energy even though physical laws described by such a model dictate the range of potential reactions that can be catalyzed in support of milk production. The problem of model scale is better addressed by using layered models with overlapping function and scope (Figure 1). Less aggregated models of underlying function can be used to assess critical biological aspects of the problem of interest at that level of function. Having formulated and parameterized such a model, it can then be used to develop more aggregated functions for incorporation into higher-level models. In such a manner, a research model can be developed at the whole animal level and used to determine critical components to be included in an application model. The application model can be equivalent to the research animal model or, more likely, will be a reduced version of the research model. The reduction in complexity as one moves from molecular models through to an application animal model is achieved by careful testing of each model to determine what aspects are critical in the more aggregated models. Such an approach allows deployment of models that are less complex for field use while maintaining the ability to utilize a broad range of more complex models for interpretation and integration of experimental data. The concept of level of aggregation in modeling is more thoroughly addressed by France and Thornley (1984) and Bywater (1984), and the overall topic is addressed in more detail by Baldwin (1995).

Given that the current NRC model represents the application animal model, a less aggregated model is needed for research purposes. There are at least 3 animal-level models that are less aggregated than the NRC: the Cornell Net Carbohydrate and Protein System (CNCPS), the model of Baldwin et al. (1987a,b,c; referred to as Molly), and the model of Danfaer (1990). Although the Cornell Net Carbohydrate and Protein System represents ruminal metabolism in greater detail than NRC, its representation of postabsorptive metabolism is common with NRC. Both Molly and the model of Danfaer represent postabsorptive metabolism in much greater detail than NRC. Of these, the project has elected to use Molly, which is depicted in simplified form in Figure 2. Use of Molly confers at least 3 benefits: 1) it can inherently represent a broader array of biological phenomena within the current structure thus allowing use of more data when testing or improving 


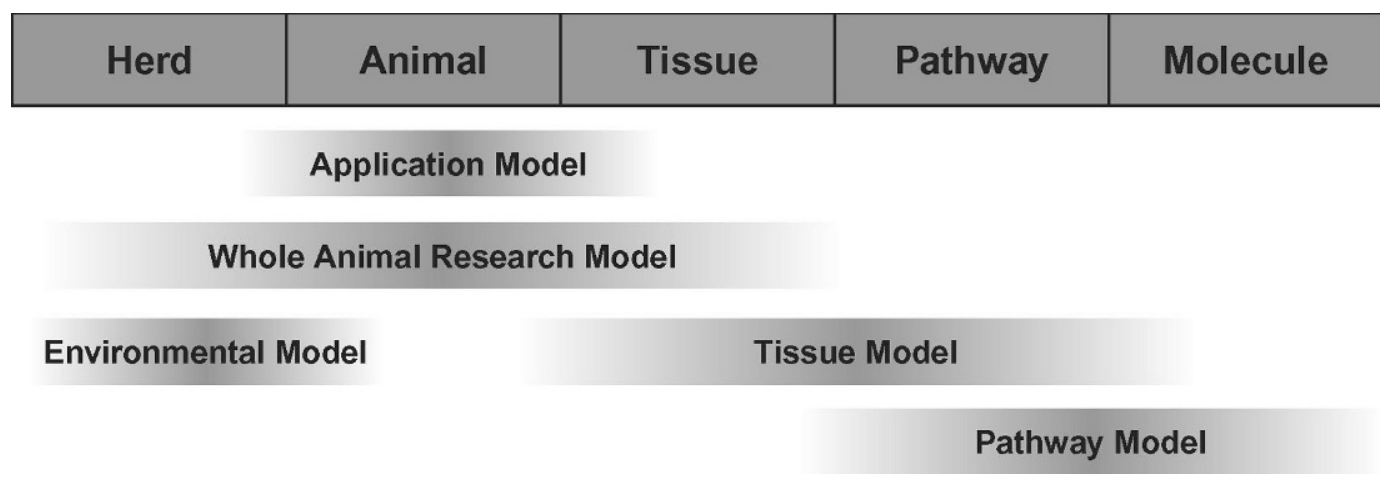

Figure 1. A depiction of model scope and aggregation as applied to an animal production system.

the model; 2) its structure and the conservation of mass principles used in developing that structure allow easier modifications when attempting to represent additional mechanisms; and 3) the model is dynamic allowing simulations in time. This latter attribute is beneficial as systemic changes over time often yield significant additional information over single snapshots. It should be noted that the model of Danfaer (1990) also possesses all 3 of these properties.

The approach used by Baldwin et al. (1987a,b,c) in constructing the model was to represent chemical entities and their flow through the metabolic system; for example, starch to glucose, glucose to lactose, to lactate, $\mathrm{CO}_{2}$, et cetera. Key regulatory pathways were represented in aggregate and energy transformations associated with those pathways were also represented. Additionally the model was represented in compartmental format with dynamic representations of compartment size. This allows tracking of body mass and composition through lactation. Thus, the model can be tested against nutrient flux data, calorimetry data, and mass accumulation data. Although these representations appear complex, the underlying elements of the model are relatively simple in terms of the array of mechanisms represented. Much of the complexity is associated with tracking energy transformations. This attribute may not be critical to an application model but is certainly beneficial in a research model.

Researchers in the United States, Scandinavia, The Netherlands, Britain, Canada, and New Zealand have worked with the model and remarkably few errors have been identified in the code. Thus, the model appears to be a robust representation of metabolism with respect to code accuracy. Certainly, much additional work is needed to identify areas where existing knowledge is limiting, and to focus both modeling and experimental efforts on those areas.

Initial work with the model identified several areas of knowledge deficiency that led to significant experi- mental work at the tissue level. More basic information has been integrated and interpreted with tissue or lower level function models (Baldwin et al., 1976; Baldwin and Koong, 1977; Waghorn and Baldwin, 1984; Argyle and Baldwin, 1988, 1989; Freetly et al., 1993a; Hanigan and Baldwin, 1994; France et al., 1995, 1997, 1999; Dijkstra et al., 1997; Hanigan et al., 1998; Johnson et al., 1999; Hanigan et al., 2001a, 2004a,b; Reichl and Baldwin, 1975). These more detailed tissue models were designed for use with the more invasive measurements commonly made by nutritionists over the past $30 \mathrm{yr}$ including interpretation of tracer data. Cellular and molecular models will be required to interpret and integrate the proteomic and genomic information that is currently being collected.

\section{MOLLY EVALUATIONS}

Regardless of scale, model evaluation is a critical component of the process. In the absence of such an effort, model development will not consistently progress. Evaluations are particularly important as model complexity increases. The initial representation of the model must be carefully assessed and deficiencies in structure or parameterization identified for subsequent attention. After each model change, another round of evaluations should be undertaken to assess whether the change was beneficial. Several evaluations of Molly have been undertaken although none are a comprehensive assessment of all model components. This is not surprising given the complexity of the model. But certainly the evaluations that have been undertaken have yielded useful insight as to research and modeling areas that need to be addressed.

At the time Molly was constructed, tools were not available for data fitting within the simulation program used. Thus, Baldwin et al. (1987a,b,c) used parameter estimates derived from more empirical models or submodels or they estimated parameters without the aid 


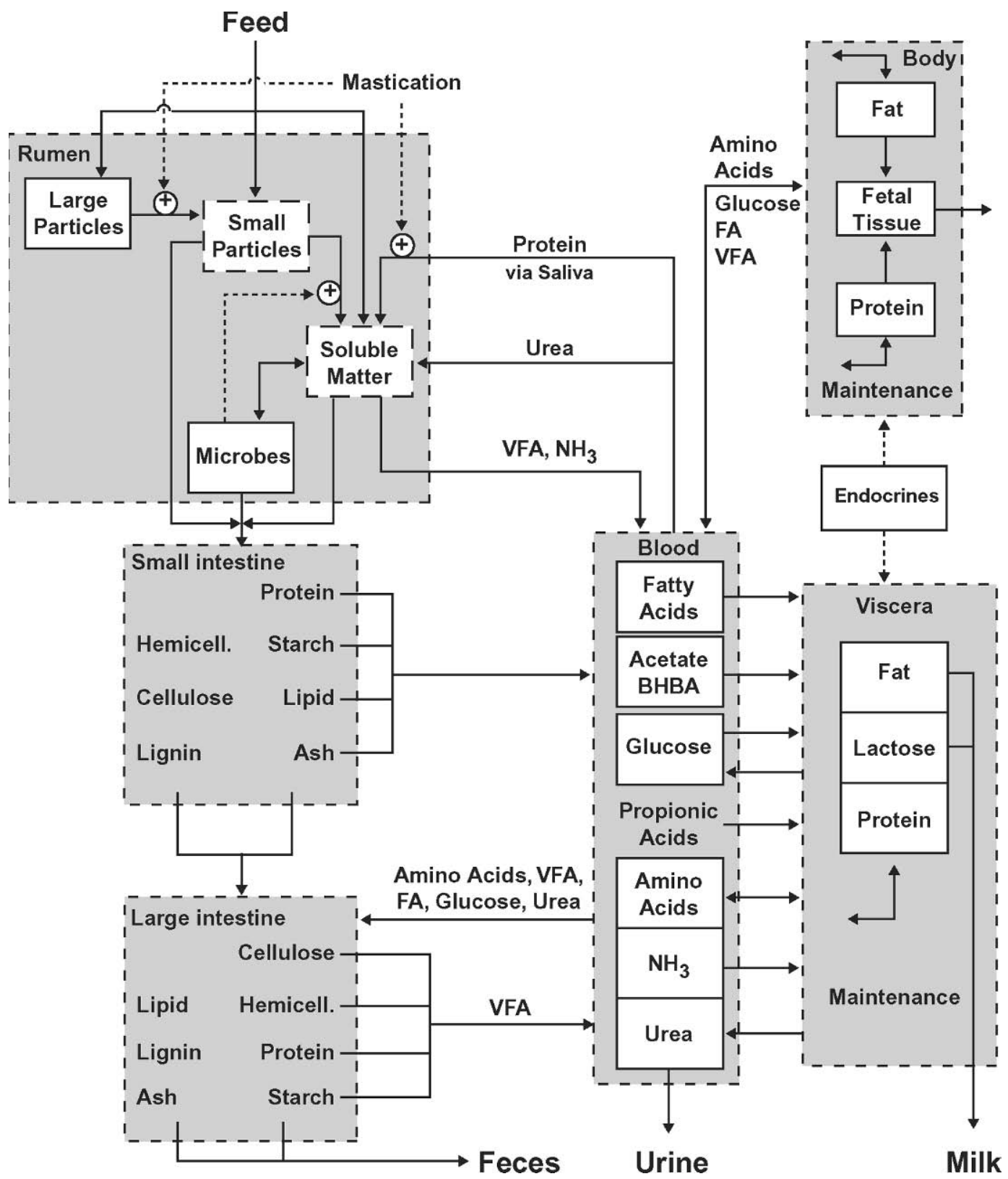

Figure 2. A schematic of the model of Baldwin et al. (1987a,b,c). Boxes with dashed lines represent compartments; boxes with solid lines represent pools; arrows represent fluxes; and $\oplus$ represent activators.

of statistical tools. Since that time at least 2 efforts have been undertaken to include parameter estimation routines within the Advanced Continuous Simulation Language (ACSL) environment. Currently such software is available from the Aegis Technologies Group (Huntsville, AL). This software supports parameter estimation as well as the ability to easily evaluate model accuracy.

\section{Digestive Evaluations}

At least 3 evaluations of the digestive elements of Molly have been conducted (Kohn et al., 1994; Hanigan et al., 2002, 2005). The evaluations of Hanigan et al. (2005) were conducted using much of the same data as used to construct the most recent NRC model. Briefly, that data set was assembled from the literature and thus includes only treatment means. Data were se- 
Table 1. Prediction errors for digestive measures when using the model of Baldwin (1995; Molly) as observed by Hanigan et al. (2005) and values reported by NRC $(2001)^{1}$

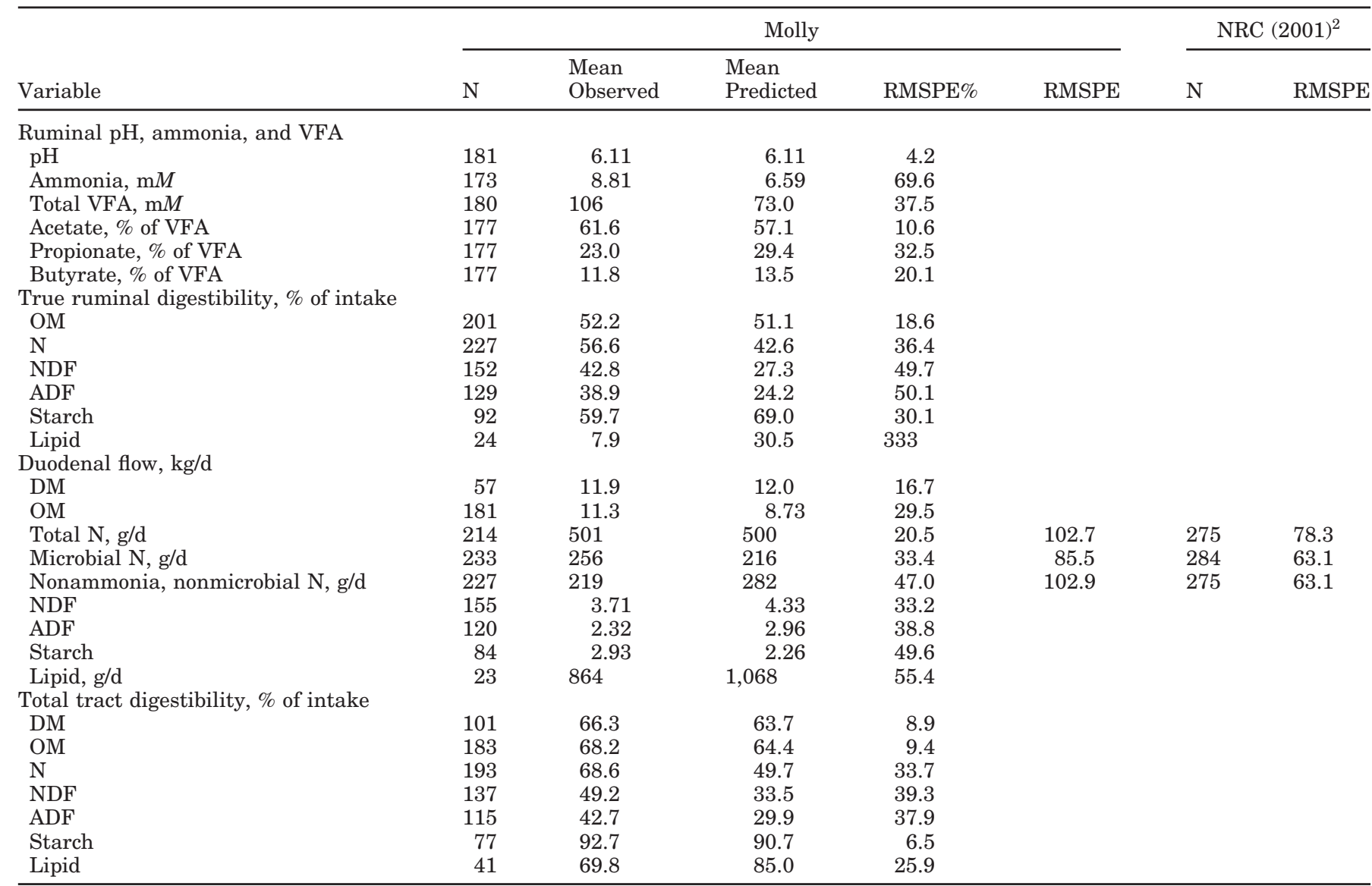

${ }^{1}$ Inputs were individual ingredients. Root mean square prediction errors (RMSPE) were expressed as a percentage of the mean observed values $(\%)$ or in units of the measurement.

${ }^{2}$ Values for NRC evaluations were taken directly from the NRC (2001).

lected for inclusion based on several criteria including the reporting of dietary ingredient inclusion rates, DMI, and some digestive measurements. The resulting data set contained 233 treatment means from 62 studies. Most observations were from lactating cows. Because no studies were used that were not also used by NRC (2001), the evaluations should be comparable. A synthesis of the available information is provided in Table 1. Data were expressed as root mean square prediction errors (RMSPE), which are calculated as the square root of the sum of the squared residual errors divided by the number of observations $\left(\sqrt{ }\left\{\left[\Sigma\left(\mathrm{Obs}_{\mathrm{i}}-\mathrm{Pred}_{\mathrm{i}}\right)^{2}\right] / \mathrm{N}\right\}\right)$ as described previously (Bibby and Toutenberg, 1977). This calculation yields an estimate of the overall variation in the predictions with units identical to the source data. It also can be divided by the mean observed measurement and multiplied by 100 yielding a value expressed as a percentage of the observed mean, which is analogous to a coefficient of variation. The latter provides a method to reference relative errors across measurements. The RMSPE can also be partitioned into mean bias, slope bias, and dispersion errors as demonstrated in Figure 3. These values are generally expressed as a percentage of the mean square prediction error and thus indicate the proportion of the overall variation that is accounted for by mean bias, slope bias, and dispersion. The 3 errors sum to 100 by definition. Note that these must be partitioned from the mean square prediction errors because the root errors are not additive.

The presence of mean or slope bias error is indicative of a model parameterization or formulation problem, and efforts should be directed to resolving those issues. Once resolved, the model should provide unbiased predictions with variance as indicated by the RMSPE. Additional improvements in the model may be achieved by assessing the cause of dispersion error; that is, the variation not explained by the model. If dispersion error is equivalent to random sampling and analytical error, then one may presume that all relevant mechanisms 

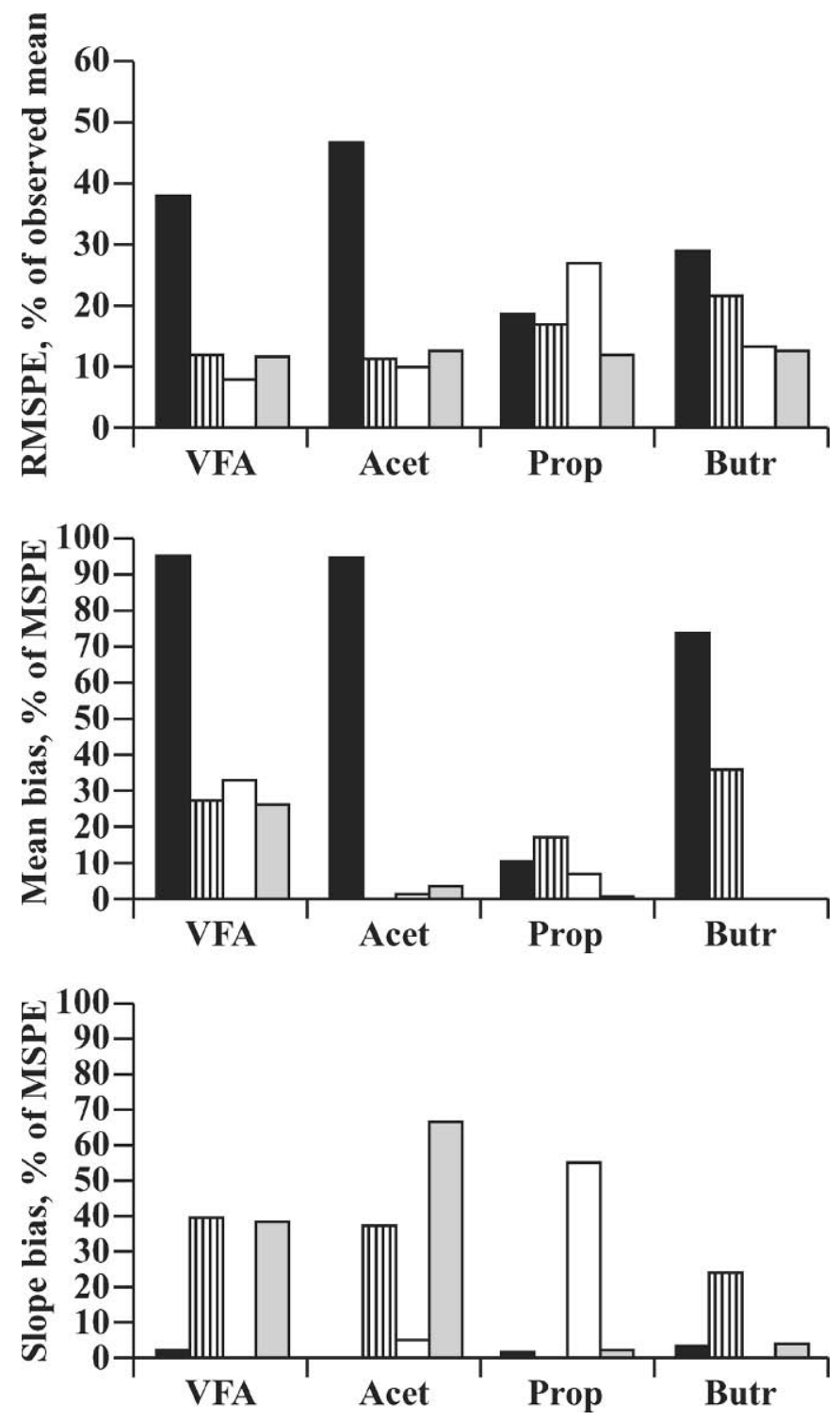

Figure 3. Root mean square prediction errors (RMSPE), mean bias errors, and slope bias errors for predictions of total VFA concentrations and the proportion of VFA represented by acetate (Acet), propionate (Prop), and butyrate (Butr) by the model of Baldwin (1995) as published (black bars), with digestion rate parameters refitted to observed duodenal flow data (striped bars), with fitted digestion rates plus the VFA absorption submodel of Dijkstra et al. (1993; white bars), and with fitted digestion rates, the absorption model of Dijkstra et al. (1993) with absorption rates refitted to the data (gray bars). Data used were collected at the Purina Mills research center at Gray Summit, MO. Adapted from Hanigan et al. (2002).

with respect to the problem have been properly encoded and parameterized in the model. When dispersion error exceeds sampling and analytical error, additional mechanisms must be considered in the model to improve RMSPE.

An obvious difference between NRC (2001) and Molly evaluations is the breadth of predictions simulated by
Molly compared with NRC (2001). Of the 28 measures of digestive function that could be simulated by Molly, only 3 were evaluated by NRC (2001). Additional predictions could have been evaluated; that is, total tract digestibility of protein, fiber, and lipid by NRC (2001), but the breadth of predictions provided by the model is clearly much narrower than that provided by the NRC (2001) model. Thus, any conclusions regarding the comparison of the 2 models must be restricted to simply duodenal $\mathrm{N}$ flow. This underscores the need as identified above for a layered approach to model development.

Predictions of duodenal flows of DM and total $\mathrm{N}$ by Molly were found to have RMSPE of 16.7 and 20.5\%, respectively, with minor proportions of the error associated with mean or slope bias. However, microbial and nonammonia, nonmicrobial (NANMN) $\mathrm{N}$ were predicted with mean bias; microbial $\mathrm{N}$ being underpredicted and NANMN overpredicted. Both NDF and ADF flows were overpredicted. Adjustment of the rate constant for digestion of these fiber entities and for protein digestion such that duodenal flow was predicted without bias would result in approximately $0.65 \mathrm{~kg} / \mathrm{d}$ greater substrate supply in the rumen to support microbial growth. However, starch flows were underpredicted by $0.67 \mathrm{~kg} / \mathrm{d}$. Thus, it is not clear at this point whether microbial mean prediction bias would be addressed by a simple reparameterization of the model. Certainly reparameterization should address the mean bias problems with fiber, starch, and NANMN flows. Currently, none of these flows exhibit significant slope bias suggesting that the model structure is adequate. However, Petruzzi et al. (2002) observed good concordance among predicted and observed flows of fiber, $\mathrm{OM}$, and $\mathrm{N}$ from the rumen when a representation of large particle passage from the rumen was included. Because large particles are assumed to be retained in the rumen in Molly, it is not clear whether additional accuracy could be achieved by alternative representations. Despite the obvious parameterization problems, $\mathrm{N}$ flow is predicted with only slightly less accuracy than the predictions of NRC (2001). Resolution of these deficiencies may result in superior predictions as compared with NRC (2001). If that is indeed true, a revised version of Molly could be used to identify key missing concepts in NRC (2001) that could be adopted from Molly.

Mean predicted lipid flow to the small intestine was also found to be overpredicted suggesting that microbial use is greater than that assumed for microbial membrane synthesis. The bias is approximately $200 \mathrm{~g}$ of lipid/d. Because microbial flow is underpredicted by 250 $\mathrm{g} / \mathrm{d}$, this error would increase if microbial flow were predicted without bias. There are thus 2 likely causes for the error: 1) The assumed lack of lipid catabolism in the rumen is incorrect; or 2) either lipid flow at the 
duodenum or lipid intake or both were measured with bias. Moate et al. (2004) have developed a lipid submodel for the Cornell-Penn-Miner (CPM) Dairy model that includes digestibility and flow predictions for a number of fatty acids as well as total lipid. Their summary of the data indicated that duodenal flow was approximately equal to dietary intake, on average. This contrasts with Molly predictions of lipid flow at the duodenum that were greater than dietary intake. Thus, assuming intake and duodenal lipid flows are unbiased, the problem would appear to be associated with a failure to represent lipid catabolism in the rumen. Adoption of principles used in Moate et al. (2004) or the whole submodel would likely address the current problems.

Observed bias in ruminal ammonia concentrations are at least partially associated with the underpredictions of feed protein degradation in the rumen. However, the magnitude of the bias suggests that the absorption rate may be poorly estimated. Another possibility is the lack of a representation of urea diffusion from blood into the rumen. Urea influx is represented solely as a function of salivary flow; that is, that transported in saliva. Clearly this influx is a significant contributor to ruminal $\mathrm{N}$ balance and is partially driven by blood urea concentrations (Lapierre and Lobley, 2001). Lack of consideration of such a mechanism is of even greater concern when dietary protein is reduced significantly. Remond et al. (2002) observed significant net influx of $\mathrm{N}$ into the rumen when ruminal ammonia fell below $9.5 \mathrm{mg} / \mathrm{dL}$, which would be expected to occur at approximately $14 \%$ dietary protein. If the model is to be used to assess the impact of low ruminally degradable protein on microbial growth and metabolism, the representation of $\mathrm{N}$ cycling needs to be improved and fitted to existing data.

Ruminal VFA were underpredicted and the proportions of individual VFA were not predicted accurately. This has been reported previously for this model (Kohn et al., 1994; Hanigan et al., 2002) as well as for the model of Dijkstra (Dijkstra et al., 1992; Neal et al., 1992; Dijkstra, 1994). Both models are based on the VFA production submodel as described by Murphy et al. (1982). Bannink et al. (1997) subsequently determined that the problem likely was associated with either absorption kinetics or the VFA production submodel. Dijkstra et al. (1993) explored driving variables for in vivo absorption of VFA and derived a more complex absorption submodel. However, when Hanigan et al. (2002) systematically explored the problem, adoption of the absorption submodel did not resolve the problem (Figure 3). Simply refitting digestion parameters to assure that the appropriate amount of substrate was being fermented significantly reduced the mean bias for total VFA, acetate percentage, and butyrate percentage; however, it introduced slope bias for all 3 predictions. Adoption of the Dijkstra et al. (1993) absorption model did not significantly affect the RMSPE for total VFA, but reduced the accuracy of propionate predictions due to increased slope bias, and butyrate predictions were improved. Fitting the Dijkstra absorption rates to the data reduced the slope bias for propionate but introduced slope bias for total VFA and acetate percentage suggesting that the problem lies with the VFA production submodel. It seems likely that VFA production is not a simple linear relationship of substrate inputs and $\mathrm{pH}$ as currently represented. Work is clearly needed in this area if VFA production patterns are to be predicted with any degree of accuracy. Because each of the VFA plays an important role in metabolism with respect to substrate supply, endocrine signals (Sano et al., 1995), and overall energetic efficiency (Baldwin, 1968), such predictive ability seems critical to continued progress in model development. Kohn and Boston (2000) have explored the role of thermodynamics in controlling microbial metabolism and have postulated that patterns of VFA production are influenced by such forces. If this proves true, improvements in VFA predictions by Molly will require adoption of equations describing such effects.

Total tract digestibility of DM is slightly overpredicted due to significant overpredictions of $\mathrm{N}$, fiber, and lipid digestibility. This would lead to overpredictions of total nutrient supply to the postabsorptive system particularly given that lipid is one of the nutrients in error. A portion of the error is related to ruminal predictions particularly for fiber. However, postruminal apparent digestion coefficients for protein and lipid are significantly less than the assumed digestibilities used for both Molly and the NRC model. Again, it is not clear whether any portions of these errors are associated with measurement problems. Clearly some of the challenge with $\mathrm{N}$ digestion relates to microbial growth in the hindgut, which is not represented in Molly.

\section{Postabsorptive Evaluations}

The postabsorptive elements of Molly have been less thoroughly evaluated than the digestive elements. This lesser activity is due, in part, to the ordered process of the system. It is difficult to evaluate postabsorptive elements when digestive inputs to that portion of the model are biased. Despite this current limitation, at least 2 areas of postabsorptive bias appear to exist. First, BW changes are overly responsive to dietary inputs (McNamara and Baldwin, 2000). Second, milk composition is inappropriately predicted with respect to stage of lactation (Hanigan et al., 2001b). 


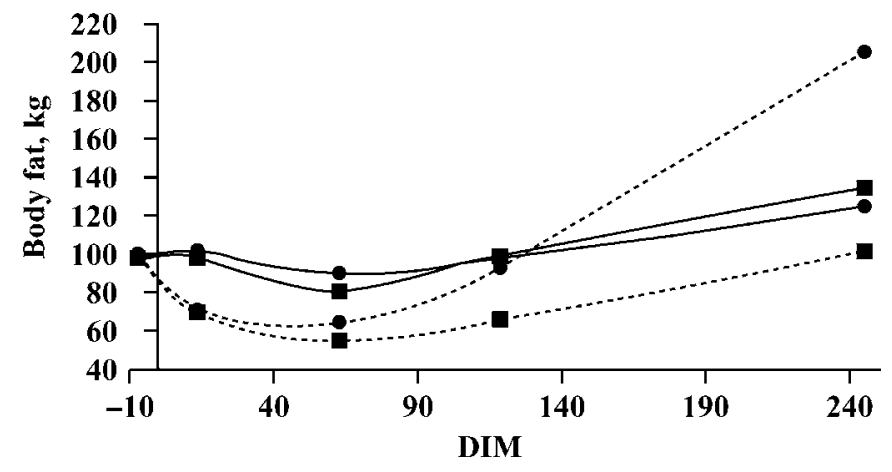

Figure 4. Predicted (broken lines) and observed (solid lines) body

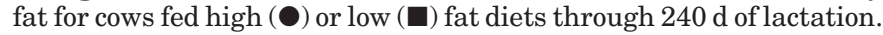
Adapted from McNamara and Baldwin (2000).

Simulations of BW change are presented in Figure 4. The model predicts the direction of weight change appropriately; however, weight loss in early lactation is overpredicted as is weight gain in late lactation, particularly when a high fat diet is fed. Because the model is constructed using conservation of mass and energy principles, these changes in BW must be reflective of an inappropriate rate of energy use for one or more postabsorptive processes, although a portion of the problem is likely due to biased estimates of fat absorption from the intestinal tract. Such input bias likely explains the divergence in weight gain on control vs. high fat diets observed by McNamara and Baldwin (2000). However, any reduction in lipid digestibility would exacerbate weight loss bias in early lactation.

McNamara (2004) explored changes in basal energy metabolism and deduced that such changes could not explain the bias throughout lactation. Changes in basal energy expenditures adequate to address late lactation weight gain resulted in even greater weight loss in early lactation. Hanigan et al. (2001b) observed that milk fat and protein were underpredicted in early lactation and late lactation and overpredicted at peak and midlactation (Figure 5). Energetically, this bias has the inverse shape of the BW bias and thus appears to explain a portion of the problem as evidenced by significant reductions in errors of prediction for BW and fat.

Another potential contributor to the weight gain problem in late lactation could be the lack of consideration of energy and protein use in support of gestation. Although gestational status is often not reported for feeding studies in the literature, it would seem likely that most cows on such studies in late lactation would be pregnant; thus, lack of consideration of energy and protein needed to support gestation would bias predictions of weight gain. Equations describing fetal and placental growth have been formulated (Koong et al.,

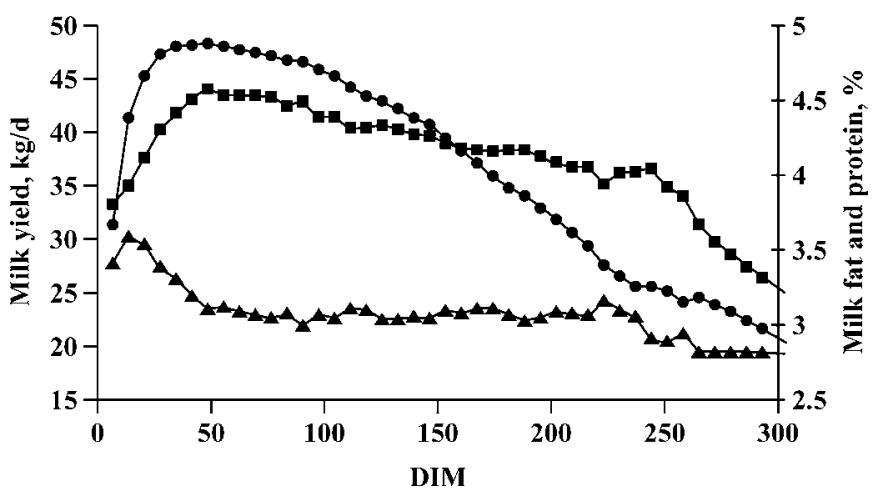

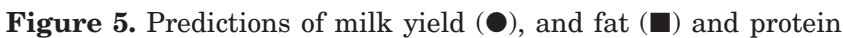
(A) content by the model of Baldwin (1995) with respect to stage of lactation. Adapted from Hanigan et al. (2001b). Inputs were the mean observed initial BW, weekly DM intake, and weekly diet composition for a group of cows housed at the Purina Research Farm in Gray Summit, MO.

1975) and used to describe gestational development in beef animals (Ferrell et al., 1976). Such equations could easily be fitted to dairy data (Bell et al., 1995) and used to define nutrient use in support of gestation within the Molly framework, which would likely reduce weight gain bias in the latter stages of lactation.

Preliminary work (M. D. Hanigan, unpublished data) suggests that adoption of revised representations of milk composition, consideration of gestational requirements, and a slight reduction in basal energy expenditures would largely address the general tendency to overpredict losses in early lactation and gains in late lactation. However, the model still tends to overpredict weight change and underpredict milk yield change in response to varied nutritional inputs as observed by McNamara and Baldwin (2000).

There are a plethora of examples where milk yield is affected by nutritional inputs. The work of Aston et al. $(1994,1995)$ clearly demonstrates the elasticity of lactational responses to nutrient supply. The pattern of responses observed by Aston and coworkers is duplicated by Molly; however, the magnitude of the milk yield response is not duplicated (M. D. Hanigan, unpublished data) resulting in excessive changes in BW. This work suggests that the current representation of mammary cell numbers and mammary enzyme activity appears to be inadequate. Vetharaniam et al. (2003) represented mammary cells as 2 pools, active and quiescent, and proposed that interconversion between the pools was driven by various factors including nutritional status and milking frequency. We have incorporated this concept into a version of the Baldwin model, but it has not been fully evaluated with a comprehensive data set. One of the major shortcomings appears to be quantita- 
tive aspects of endocrine control of total mammary activity (active secretory cells or activity per cell). The modeling work suggests that lipostatic signals may regulate mammary activity. If true, it would help explain the current insensitivity to energy supply. However, knowledge of the mechanisms involved in regulating cell numbers and activity, particularly with respect to quantitative aspects of the problem, are limiting; thus, further modeling progress in the area will be hampered by lack of core knowledge.

Although there are deficiencies in Molly, reparameterization with existing data would likely address a number of these problems and the postabsorptive problems are partially related to a lack of knowledge. Consequently, the framework is adequate to begin to evaluate and unravel more complex problems related to regulation of nutrient metabolism. Progress in this latter area is critical if we are to achieve the goal of fully representing variable efficiencies of use of $\mathrm{ME}$ and to better represent metabolism of individual amino acids. It is encouraging that evaluation of digestive elements with an independent data set yields prediction errors for duodenal $\mathrm{N}$ flow that are only slightly greater than those observed for NRC (2001), which was fitted to the data (Table 1).

\section{MOLLY DEVELOPMENT}

Although the basic structure of Molly has proven to be generally adequate, some modifications have been undertaken. Consideration of temporal aspects of dietary input changes for a given animal or group of animals that are to be simulated has posed a challenge within the ACSL framework. Although changes can be accommodated, implementing those changes automatically within a parameter estimation environment was not possible. To address this problem an input scheme using matrices to hold input vectors for each animal or group was devised and implemented within the model (Hanigan et al., 2005). This allows preloading of all dietary conditions including observed intakes so they can be referenced by the code as the simulation progresses.

Although the model was originally conceived with inputs of dietary nutrients, such an approach does not lend itself to direct diet optimization. Diet optimization can be achieved, but the process would be discontinuous wherein Molly could be used to define the optimum dietary nutrient profile, which could then be used to constrain a second optimization that derived a set of ingredients that achieved the desired nutrient profile. The obvious limitation to this approach is the discontinuity, which requires one to assume fixed economic values for each dietary nutrient to achieve a least-cost formulation of nutrients. In reality, the economic value of a given nutrient varies depending on the mix of ingredients offered to the model, nutrient constraints, and the formulation space (equivalent to intake when balancing an entire ration). For example, the cost of a given amount of a nutrient will increase as formulation space is limited, other nutrient inclusions are increased, or the minimum inclusion of the desired nutrient is increased. In other words, the value of a unit of protein in a $16 \%$ protein diet is not generally equivalent to the value of a unit of protein in a $24 \%$ protein diet. Thus, if one desires to use the model to optimize dietary ingredients, an ingredient input scheme is needed.

Hanigan et al. (2005) converted model inputs to an ingredient-based scheme. Additionally, they developed a version of the model that was linked to a nonlinear optimizer (Boston and Hanigan, 2005) and configured the code to allow optimization of a variety of variables including feed cost, income over feed cost, milk value, milk yield, milk component yield, and $\mathrm{N}$ in waste. Each of these variables could be minimized or maximized and multiple variables could be considered in a single solution. The problem could be constrained by a number of linear and nonlinear variables. Linear constraints included dietary nutrient concentrations and ingredient inclusion rates. Nonlinear constraints included essentially any model variable including ruminal $\mathrm{pH}$, BCS, ending BW, milk yield, and milk composition. All of these constraints could be set as minimum, maximum, or equality constraints.

A scheme was also devised to relate the 3-pool protein degradation scheme and associated degradation rate constant of NRC (2001) to the 2-pool protein scheme used in Molly. This modification provides a method to adjust the protein degradation rate of the model to reflect the inherent degradation characteristics of the feeds used to construct the diet. This modification is consistent with the approach used by others (NRC, 2001) and appears to generally predict NANMN responses when evaluated with a limited data set (Bateman et al., 2001). Bateman et al. (2005) evaluated the accuracy of the submodel and tabular NRC data in predicting observed duodenal NANMN flows for a much larger data set and found the predictions to explain $66 \%$ of the observed variation although there was an observed linear bias to the predictions. Thus, it would seem that representation of changes in intrinsic rates of protein degradation within the model is appropriate; however, the quantitative impact of this change is not currently clear and merits additional work.

These modifications have resulted in a model that has many aspects needed for deployment as an application model. This starts to achieve the goal of having a research animal model that includes enough description 
of underlying function to allow the use of the majority of whole animal data normally collected during in vivo experiments. It also includes enough aspects of the application model to allow the full range of testing and exploration needed to identify key elements that should be extracted for deployment in the application model.

\section{TISSUE MODEL DEVELOPMENT}

Additional work describing metabolism in several tissues has been undertaken over the past $30 \mathrm{yr}$ including descriptions of ruminal (Baldwin et al., 1977; Dijkstra et al., 1992; Russell et al., 1992; Chilibroste et al., 2001), hepatic (Waghorn, 1982; Freetly et al., 1993b; Danfaer, 1994; Hanigan et al., 2004a), mammary (Waghorn and Baldwin, 1984; Hanigan and Baldwin, 1994; Hanigan et al., 2001a), and adipose tissues (Baldwin, 1995), as well as an initial effort to describe portal-drained viscera metabolism (Hanigan et al., 2004b). These efforts have provided an initial framework of tissue metabolism models that can be drawn on for data integration and interpretation efforts and have highlighted areas of knowledge deficiency that are limiting forward progress. A challenge with much of the earlier work is that computing power and tools required to parameterize and thoroughly test the models using large data sets was not available. Thus, the current literature has not been fully leveraged with respect to development and testing of these models. Despite past limitations, the tissue modeling work has provided information pertinent to improving existing animal models as well as identifying areas where knowledge is lacking.

Work with isotope tracer models indicates that early estimates of protein turnover used in Molly are likely too low. Use of long-term infusions in the early work ignores the impact of protein pools that turn over rapidly. More recent estimates in the lactating mammary glands indicate that protein turnover is at least $50 \%$ per day (Champredon et al., 1990) rather than the $8 \%$ currently used. Presumably, turnover in other visceral tissues is also underestimated. If so, reparameterization of protein turnover in Molly would significantly increase basal metabolic rates and reduce weight gain bias.

A systematic evaluation of liver and a more limited evaluation of portal-drained viscera metabolism demonstrated that AA clearance by those tissues appears to be by mass action. Thus, as AA inputs increase, AA clearance from blood increases with no apparent regulation of the activity (Hanigan, 2005). However, extraction kinetics have not been examined under a wide range of nutrient inputs other than varying AA inputs. It is possible that extraction could vary in association with varying energy status.
Conversely, mammary AA extraction appears to be highly regulated such that transport activity is enhanced when AA supply is limiting, and reduced when in excess (Bequette et al., 2000). Additionally it was observed that the often-used representation of protein synthesis as a function of only the first-limiting AA is not the best representation of milk protein synthesis. Hanigan et al. (2000) demonstrated that a multisubstrate approach, in which multiple AA could be simultaneously dictating rates of protein synthesis, reduced both overall prediction errors and mean prediction bias.

Partitioning of AA to mammary tissue could be expected to be a function of AA supply as well as rates of use for milk protein synthesis. Such regulation of partitioning is problematic with respect to the current fixed representation of postabsorptive efficiencies of AA use. Incorporation of these concepts into Molly and eventually in some form in application models should improve our predictions of $\mathrm{AA}$ and $\mathrm{N}$ metabolism allowing more precise estimates of postabsorptive efficiency, which should lead to reductions in $\mathrm{N}$ inputs and environmental impact.

Additional work is needed to develop methods to integrate data derived from microarrays and proteomic efforts with existing models of metabolism. Efforts have been undertaken to integrate metabolic and gene expression data on a broad scale (Chan et al., 2003). These efforts have generally used a matrix approach to represent expression and metabolism networks with interactions either specified or derived iteratively. Interactions could be either positive or negative and were assumed to be linear. The latter assumption essentially ignores the historical efforts in metabolic modeling. Future work is needed to leverage existing models of metabolism. For example, the major metabolic pathways are represented in the model of Freetly et al. (1993a). If one were to collect both metabolic and gene expression data related to liver function, it seems logical to use such a metabolic model as the model to integrate metabolism data while considering the effects of changes in the expression level of major regulatory genes such as pyruvate kinase and pyruvate carboxylase (Greenfield et al., 2000).

This approach could be extended if methods were available to measure more easily metabolite concentrations and enrichment. Currently, nuclear magnetic resonance spectroscopic methods appear promising. Bertram et al. (2005) have demonstrated their utility for measuring a range of metabolites in bovine blood and these methods have been used for complete flux analyses in bacteria (Dauner et al., 2001). Further development of these analytical methods would allow more complete assessments of metabolic profiles and flux estimates that could be paired with the more comprehen- 
sive microarray data currently being collected. This effort must eventually include consideration of proteomic changes as well. Although analytical techniques are progressing in each of these areas, much additional work is needed to begin to integrate the information into mathematical systems.

In summary, Molly offers an excellent framework for integration of data at several levels of aggregation, and thus serves as a potential tool for deriving improvements for an application model such as NRC (2001). It could also serve as an application model directly. The current code is apparently free from error and represents many key aspects of metabolism. Although parameter estimation work is needed to address bias in digestive predictions, $\mathrm{N}$ flow predictions have similar errors as the NRC (2001) model. Reparameterization should only improve accuracy. The postaborptive system has been less thoroughly tested, but offers an excellent tool for further exploration of intermediary metabolism. Model behavior with respect to experimental observations indicates that our understanding of metabolic regulation may still be inadequate. The model is designed to allow relatively easy integration of new mechanisms, and these mechanisms can be developed with the myriad of existing tissue models. Work with the tissue models has already identified at least 2 deficiencies in current representations of metabolism at the animal level. Future progress at the tissue, cellular, and molecular levels will require model development work to allow integration of high-density gene expression, protein expression, and metabolism data. Gains in knowledge using these tools can be integrated into application models using a disciplined approach in which key concepts are transferred in an aggregated form from basic cell or pathway models up through a whole animal research model to an application model. But diligence is needed to ensure that models at all levels of aggregation are thoroughly tested against experimental observations before derivation of key concepts is undertaken. Often, what appear to be our best ideas do not warrant inclusion in a production model because they are not critical determinants of animal performance.

\section{REFERENCES}

Argyle, J. L., and R. L. Baldwin. 1989. Effects of amino acids and peptides on rumen microbial growth yields. J. Dairy Sci. 72:2017-2027.

Argyle, J. L., and R. L. Baldwin. 1988. Modeling of rumen water kinetics and effects of rumen $\mathrm{pH}$ changes. J. Dairy Sci. 71:1178-1188.

Aston, K., J. D. Sutton, and W. J. Fisher. 1995. Milk production from grass silage diets: Strategies for concentrate allocation. Anim. Sci. 61:465-480.

Aston, K., C. Thomas, S. R. Daley, J. D. Sutton, and M. S. Dhanoa. 1994. Milk production from grass silage diets - effects of silage characteristics and the amount of supplementary concentrate. Anim. Prod. 59:31-41.

Atwater, W. O., and A. P. Bryant. 1900. The availability and fuel value of food materials. In Annual Report of the Storrs, Connecticut Agricultural Experiment Station, Storrs, CT.

Baldwin, R. L. 1995. Modeling ruminant digestion and metabolism. Chapman and Hall, London, UK.

Baldwin, R. L. 1968. Estimation of theoretical calorific relationships as a teaching technique. A review. J. Dairy Sci. 51:104-111.

Baldwin, R. L., J. France, D. E. Beever, M. Gill, and J. H. Thornley. 1987a. Metabolism of the lactating cow. III. Properties of mechanistic models suitable for evaluation of energetic relationships and factors involved in the partition of nutrients. J. Dairy Res. $54: 133-145$.

Baldwin, R. L., J. France, and M. Gill. 1987b. Metabolism of the lactating cow. I. Animal elements of a mechanistic model. J. Dairy Res. 54:77-105.

Baldwin, R. L., and L. J. Koong. 1977. Dynamic model of ruminant digestion for evaluation of factors affecting nutritive value. Agric. Syst. 2:255-288.

Baldwin, R. L., L. J. Koong, and M. J. Ulyatt. 1977. A dynamic model of ruminant digestion for evaluation of factors affecting nutritive value. Agric. Syst. 2:255-288.

Baldwin, R. L., J. H. Thornley, and D. E. Beever. 1987c. Metabolism of the lactating cow. II. Digestive elements of a mechanistic model. J. Dairy Res. 54:107-131.

Baldwin, R. L., Y. T. Yang, K. Crist, and G. Grichting. 1976. Theoretical model of ruminant adipose tissue metabolism in relation to the whole animal. Fed. Proc. 35:2314-2318.

Bannink, A., H. De Visser, A. Klop, J. Dijkstra, and J. France. 1997. Causes of inaccurate prediction of volatile fatty acids by simulation models of rumen function in lactating cows. J. Theor. Biol. 189:353-366.

Bateman, H. G., J. H. Clark, and M. R. Murphy. 2005. Development of a system to predict feed protein flow to the small intestine of cattle. J. Dairy Sci. 88:282-295.

Bateman, H. G., J. H. Clark, R. A. Patton, C. J. Peel, and C. G. Schwab. 2001. Prediction of crude protein and amino acid passage to the duodenum of lactating cows by models compared with in vivo data. J. Dairy Sci. 84:665-679.

Bell, A. W., R. Slepetis, and R. A. Ehrhardt. 1995. Growth and accretion of energy and protein in the gravid uterus during late pregnancy in Holstein cows. J. Dairy Sci. 78:1954-1961.

Bequette, B. J., M. D. Hanigan, A. G. Calder, C. K. Reynolds, G. E. Lobley, and J. C. MacRae. 2000. Amino acid exchange by the mammary gland of lactating goats when histidine limits milk production. J. Dairy Sci. 83:765-775.

Bertram, H. C., N. B. Kristensen, A. Malmendal, N. C. Nielsen, R. Bro, H. J. Andersen, and D. L. Harmon. 2005. A metabolomic investigation of splanchnic metabolism using ${ }^{1} \mathrm{H}$ NMR spectroscopy of bovine blood plasma. Anal. Chim. Acta 536:1-6.

Bibby, J., and H. Toutenberg. 1977. Prediction and improved estimation in linear models. Wiley, Chichester, UK.

Boston, R. C., and M. D. Hanigan. 2005. Segmented, constrained, nonlinear, multi-objective, dynamic optimization methodology applied to the dairy cow ration formulation problem in a situation where some of the constraints may be discontinuous. Nutrient Digestion and Utilization in Farm Animals: Modelling Approaches. E. Kebreab, J. Dijkstra, A. Bannink, W. Gerrits, and J. France, ed. CAB International, Wallingford, UK.

Bywater, A. C. 1984. Use of models in management: implications for development and delivery of technical information - predicting animal response. Page 120 in Modeling Ruminant Digestion and Metabolism: Proc. 2nd Int. Workshop. R. L. Baldwin and A. C. Bywater, ed. Univ. California, Davis.

Champredon, C., E. Debras, P. P. Mirand, and M. Arnal. 1990. Methionine flux and tissue protein synthesis in lactating and dry goats. J. Nutr. 120:1006-1015.

Chan, C., D. Hwang, G. N. Stephanopoulos, M. L. Yarmush, and G. Stephanopoulos. 2003. Application of multivariate analysis to optimize function of cultured hepatocytes. Biotechnol. Prog. 19:580-598. 
Chilibroste, P., J. Dijkstra, and S. Tamminga. 2001. Design and evaluation of a non-steady state rumen model. NJAS (Wageningen J. Life Sci.) 49:297-312.

Danfaer, A. 1994. Nutrient metabolism and utilization in the liver. Livest. Prod. Sci. 39:115-127.

Danfaer, A. 1990. A dynamic model of nutrient digestion and metabolism in lactating dairy cows. PhD Thesis, National Institute of Animal Science, Foulum, Denmark.

Dauner, M., J. E. Bailey, and U. Sauer. 2001. Metabolic flux analysis with a comprehensive isotopomer model in Bacillus subtilis. Biotechnol. Bioeng. 76:144-156.

Dijkstra, J. 1994. Production and absorption of volatile fatty acids in the rumen. Livest. Prod. Sci. 39:61-69.

Dijkstra, J., H. Boer, J. Van Bruchem, M. Bruining, and S. Tamminga. 1993. Absorption of volatile fatty acids from the rumen of lactating dairy cows as influenced by volatile fatty acid concentration, $\mathrm{pH}$ and rumen liquid volume. Br. J. Nutr. 69:385-396.

Dijkstra, J., J. France, M. S. Dhanoa, J. A. Maas, M. D. Hanigan, A. J. Rook, and D. E. Beever. 1997. A model to describe growth patterns of the mammary gland during pregnancy and lactation. J. Dairy Sci. 80:2340-2354.

Dijkstra, J., H. D. Neal, D. E. Beever, and J. France. 1992. Simulation of nutrient digestion, absorption and outflow in the rumen: Model description. J. Nutr. 122:2239-2256.

Ferrell, C. L., W. N. Garrett, and N. Hinman. 1976. Growth, development and composition of the udder and gravid uterus of beef heifers during pregnancy. J. Anim. Sci. 42:1477-1489.

France, J., J. Bequette, G. E. Lobley, J. A. Metcalf, D. Wray-Cahen, M. S. Dhanoa, M. R. C. Backwell, M. D. Hanigan, and J. C. MacRae. 1995. An isotope dilution model for partitioning leucine uptake by the bovine mammary gland. J. Theor. Biol. 172:369377.

France, J., M. D. Hanigan, B. J. Bequette, J. A. Metcalf, D. E. Beever, G. E. Lobley, J. C. MacRae, and F. R. C. Backwell. 1997. A model for quantifying the contribution of extracellularly derived peptides to milk protein synthesis in the ruminant mammary gland. J. Theor. Biol. 185:379-388.

France, J., M. D. Hanigan, C. K. Reynolds, J. Dijkstra, L. A. Crompton, J. A. Maas, B. J. Bequette, J. A. Metcalf, G. E. Lobley, J. C. MacRae, and D. E. Beever. 1999. An isotope dilution model for partitioning leucine uptake by the liver of the lactating dairy cow. J. Theor. Biol. 198:121-133.

France, J., and J. H. M. Thornley. 1984. Mathematical models in agriculture. Butterworths, Sevenoaks, UK.

Freetly, H. C., J. R. Knapp, C. C. Calvert, and R. L. Baldwin. 1993a. Development of a mechanistic model of liver metabolism in the lactating cow. Agric. Syst. 41:157-195.

Freetly, H. C., J. R. Knapp, C. C. Calvert, and R. L. Baldwin. 1993b. Development of a mechanistic model of liver metabolism in the lactating cow. Agric. Syst. 41:157-195.

Greenfield, R. B., M. J. Cecava, and S. S. Donkin. 2000. Changes in mRNA expression for gluconeogenic enzymes in liver of dairy cattle during the transition to lactation. J. Dairy Sci. 83:12281236.

Hanigan, M. D. 2005. Quantitative aspects of ruminant splanchnic metabolism as related to predicting animal performance. Anim. Sci. 80:23-32.

Hanigan, M. D., and R. L. Baldwin. 1994. A mechanistic model of mammary gland metabolism in the lactating cow. Agric. Syst. 45:369-419.

Hanigan, M. D., H. G. Bateman, J. G. Fadel, J. P. McNamara, and N. E. Smith. 2005. An ingredient-based input scheme for Molly. Page 328-348 in Nutrient Digestion and Utilization in Farm Animals: A Modelling Approach. E. Kebreab, J. Dijkstra, A Bannink, W. Gerrits, and J. France, ed. CAB International, Wallingford, UK

Hanigan, M. D., L. A. Crompton, J. A. Metcalf, and J. France. 2001a. Modelling mammary metabolism in the dairy cow to predict milk constituent yield, with emphasis on amino acid metabolism and milk protein production: Model construction. J. Theor. Biol. 213:223-239.
Hanigan, M. D., L. A. Crompton, C. K. Reynolds, D. Wray-Cahen, M. A. Lomax, and J. France. 2004a. An integrative model of amino acid metabolism in the liver of the lactating dairy cow. J. Theor. Biol. 228:271-289.

Hanigan, M. D., J. France, L. A. Crompton, and B. J. Bequette. 2000. Evaluation of a representation of the limiting amino acid theory for milk protein synthesis. Page 127 in Modelling Nutrient Utilization in Farm Animals. J. P. McNamara, J. France, and D. E. Beever, ed. CABI Publishing, Wallingford, UK.

Hanigan, M. D., J. France, D. Wray-Cahen, D. E. Beever, G. E. Lobley, L. Reutzel, and N. E. Smith. 1998. Alternative models for analyses of liver and mammary transorgan metabolite extraction data. Br. J. Nutr. 79:63-78.

Hanigan, M. D., C. K. Reynolds, D. J. Humphries, B. Lupoli, and J. D. Sutton. 2004b. A model of net amino acid absorption and utilization by the portal-drained viscera of the lactating dairy cow. J. Dairy Sci. 87:4247-4268.

Hanigan, M. D., F. E. Standaert, L. Reutzel, and D. C. Weakley. 2001b. An independent evaluation of a lactating dairy cow model: 1. Milk production and composition, body weight, and body condition score. AABP Proc. 34:174. (Abstr.)

Hanigan, M. D., D. C. Weakley, F. E. Standaert, and L. R. Reutzel. 2002. Evaluation and refinement of ruminal volatile fatty acid absorption equations in a dynamic, metabolic model of the lactating dairy cow. J. Dairy Sci. 85(Suppl. 1):402. (Abstr.)

Johnson, H. A., R. L. Baldwin, J. France, and C. C. Calvert. 1999. A model of whole-body protein turnover based on leucine kinetics in rodents. J. Nutr. 129:728-739.

Kohn, R. A., and R. C. Boston. 2000. The role of thermodynamics in controlling rumen metabolism. Page 11 in Modelling Nutrient Utilization in Farm Animals. J. P. McNamara, J. France, and D. E. Beever, ed. CABI Publishing, Wallingford, UK.

Kohn, R. A., R. C. Boston, J. D. Ferguson, and W. Chalupa. 1994. The integration and comparison of dairy cow models. Page 117 in Proc. IV Int. Workshop on Modelling Nutrient Utilisation in Farm Animals. A. Danfaer and P. Lescoat, ed. National Institute of Animal Science, Foulum, Denmark.

Koong, L. J., W. N. Garrett, and P. V. Rattray. 1975. A description of the dynamics of fetal growth in sheep. J. Anim. Sci. 41:1065-1068.

Lapierre, H., and G. E. Lobley. 2001. Nitrogen recycling in the ruminant: A review. J. Dairy Sci. 84(E Suppl.):E223-E236.

McNamara, J. P. 2004. Research, improvement and application of mechanistic, biochemical, dynamic models of metabolism in lactating dairy cattle. Anim. Feed Sci. Technol. 112:155-176.

McNamara, J. P., and R. L. Baldwin. 2000. Estimation of parameters describing lipid metabolism in lactation: Challenge of existing knowledge described in a model of metabolism. J. Dairy Sci. 83:128-143.

Moate, P. J., W. Chalupa, T. C. Jenkins, and R. C. Boston. 2004. A model to describe ruminal metabolism and intestinal absorption of long chain fatty acids. Anim. Feed Sci. Technol. 112:79-105.

Murphy, M. R., R. L. Baldwin, and L. J. Koong. 1982. Estimation of stoichiometric parameters for rumen fermentation of roughage and concentrate diets. J. Anim. Sci. 55:411-421.

Neal, H. D., J. Dijkstra, and M. Gill. 1992. Simulation of nutrient digestion, absorption, and outflow in the rumen: Model evaluation. J. Nutr. 122:2257-2272.

NRC. 1978. Nutrient Requirements of Dairy Cattle. 5th ed. National Academy Press, Washington, DC

NRC. 1985. Ruminant Nitrogen Usage. National Academy Press, Washington, DC.

NRC. 1989. Nutrient Requirements of Dairy Cattle. 6th ed. National Academy Press, Washington, DC

NRC. 2001. Nutrient Requirements of Dairy Cattle. 7th rev. ed. National Academy Press, Washington, DC.

Petruzzi, H., A. Danfaer, and P. Norgaard. 2002. A dynamic simulation model of nutrient digestion in the rumen of dairy cows. J. Anim. Feed Sci. 11:367-397.

Reichl, J. R., and R. L. Baldwin. 1975. Rumen modeling: Rumen input-output balance models. J. Dairy Sci. 58:879-890. 
Remond, D., P. Noziere, and C. Poncet. 2002. Effect of time of starch supply to the rumen on the dynamics of urea and ammonia net flux across the rumen wall of sheep. Anim Res. 51:3-13.

Russell, J. B., J. D. O'Connor, D. G. Fox, S. Van, and C. J. Sniffen. 1992. A net carbohydrate and protein system for evaluating cattle diets: I. Ruminal fermentation. J. Anim. Sci. 70:3551-3561.

Sano, H., E. Nakamura, H. Takahashi, and Y. Terashima. 1995. Plasma insulin and glucagon responses to acute challenges of acetate, propionate, n-butyrate and glucose in growing gilts (Sus scrofa). Comp. Biochem. Physiol. Phys. 110:375-378.

USDA-NASS. 2005. Milk production. National Agricultural Statistics Services. Agricultural Statistics Board, U. S. Department of Agri- culture Online. Available: http://usda.mannlib.cornell.edu/reports/nassr/dairy/pmp-bb/2005/mkpr0605.pdf Accessed July 5, 2005.

Vetharaniam, I., S. R. Davis, M. Upsdell, E. S. Kolver, and A. B. Pleasants. 2003. Modeling the effect of energy status on mammary gland growth and lactation. J. Dairy Sci. 86:3148-3156.

Waghorn, G. C. 1982. Modelling analyses of bovine mammary and liver metabolism. $\mathrm{PhD}$ Thesis, Univ. California, Davis.

Waghorn, G. C., and R. L. Baldwin. 1984. Model of metabolite flux within mammary gland of the lactating cow. J. Dairy Sci. 67:531-544 